\title{
A new $\mathrm{X}$ linked syndrome with mental retardation and craniofacial dysmorphism?
}

\author{
I Hyde-Forster, G McCarthy, A C Berry
}

\begin{abstract}
We present a syndrome manifested in two half brothers and their two maternal aunts which is characterised in the two boys by severe mental retardation and craniofacial dysmorphism (broad, coarse features and marked plagiocephaly with flattened occiput), and in the aunts merely by moderate mental retardation without dysmorphic features. The brothers do not seem to fall into any previously described $X$ linked syndrome with mental retardation.

(f Med Genet 1992;29:736-8)
\end{abstract}

$\mathrm{X}$ linked mental retardation is acknowledged to be a major cause of severe learning difficulties. Surveys have shown an excess of males over females with severe mental ratardation and later studies suggested that the excess was the result of an $\mathrm{X}$ linked condition. ${ }^{1-3}$

We present two uterine half brothers with severe mental retardation and craniofacial dysmorphism whose two maternal aunts are both moderately mentally handicapped but manifest no dysmorphic features. The mother of the boys is normal both mentally and in appearance.

\section{Case reports}

CASE 1

Case 1 (IV. 1, fig 1) was born in August 1987. Apart from a flu-like illness at the end of the

Received 13 March 1992 Accepted 20 March 1992. second trimester which lasted two weeks, the obstetric history was normal. There were no neonatal problems and the first six months of life were uneventful. Between 6 and 9 months his head shape reportedly changed and his development slowed down. At 8 months he had striking plagiocephaly and a flattened occiput. He was sitting unsupported by 14 months but was visually and auditorily inattentive and had no speech. At $10 \frac{1}{2}$ months extensor spasms of up to 10 to 20 a day were reported and salaam attacks were queried. He started having myoclonic jerks which increased in frequency and then became generalised. At 4 years 4 months he has no speech, can chew and swallow without difficulty, and will open his mouth if shown a bottle, plate, or spoon. On examination he has a brachycephalic skull, plagiocephaly, a flattened occiput with a palpable indentation, and coarse features (fig 2). Head circumference $(47 \mathrm{~cm})$ is below the $3 \mathrm{rd}$ centile for age and height $(101 \mathrm{~cm})$ is on the 50 th centile. Skin, hands, feet, and genitalia are normal.

\section{Investigations}

Skull $x$ ray showed brachy/plagiocephaly with no evidence of synostosis. Chest $x$ ray was normal. Mild cerebral atrophy but no calcification was seen on CT scans and two EEGs were normal. Routine tests on blood and urine showed no evidence of infections or metabolic disease. Chromosome analysis showed a normal male chromosome complement $46, \mathrm{XY}$ (700 BPHS). There was no evidence of the fragile site on the $\mathrm{X}$ chromosomes.

\section{CASE 2}

Case 2. (IV. 2, fig 1) was born in January 1990. $\mathrm{He}$ was delivered spontaneously at term. Reduced fetal movements and baseline bradycardia had been noted since 34 weeks' gestation. There were no neonatal problems. He fed well and gained weight normally. Apart from coarse features and a largish head he was normal at 6 weeks. At 12 months he had good head control, could roll, but found it difficult to get into a crawling position. He was not doing much with his hands and did not reach out for toys. By $13 \frac{1}{2}$ months no further milestones had been reached. On examination, his skull and features were very similar to those of his brother, though his forehead appeared to be more prominent, relatively wider, and bulging outwards (fig 3). There were no other remarkable features on examination.

Figure 1 Family pedigree. 


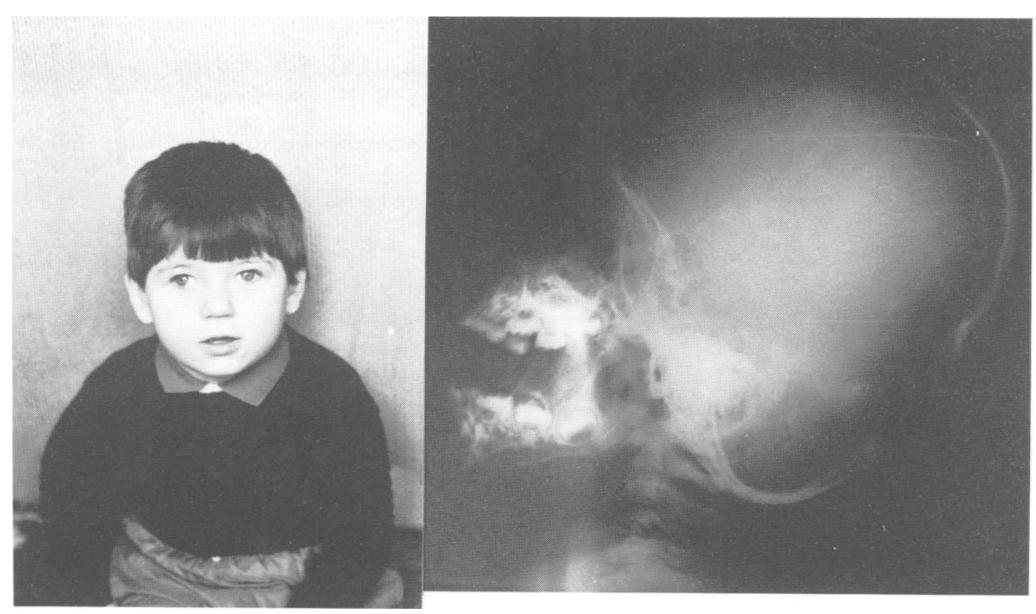

Figure 2 Case 1 aged 4 years 4 months and, lateral skull $x$ ray at 2 years.

\section{Investigations}

No evidence of $\mathrm{Hb} \mathrm{H}$ inclusions was found after staining of red cells with $1 \%$ brilliant cresyl blue.

CASE 3

Case 3 (III. 4, fig 1) was born in 1966. She had a normal obstetric and neonatal history. At 2 years developmental milestones were generally normal apart from slow language development. By 4 years the rate of progress had slowed down considerably and she was placed in the special needs category, attending schools for those with moderate to severe learning difficulties. She has good conversational skills and is capable domestically and socially needing minimal supervision. Physical examination showed no abnormal findings and she is attractive in appearance.

\section{Investigations}

Chromosome analysis showed a normal female chromosome complement, $46, \mathrm{XX}$. There was

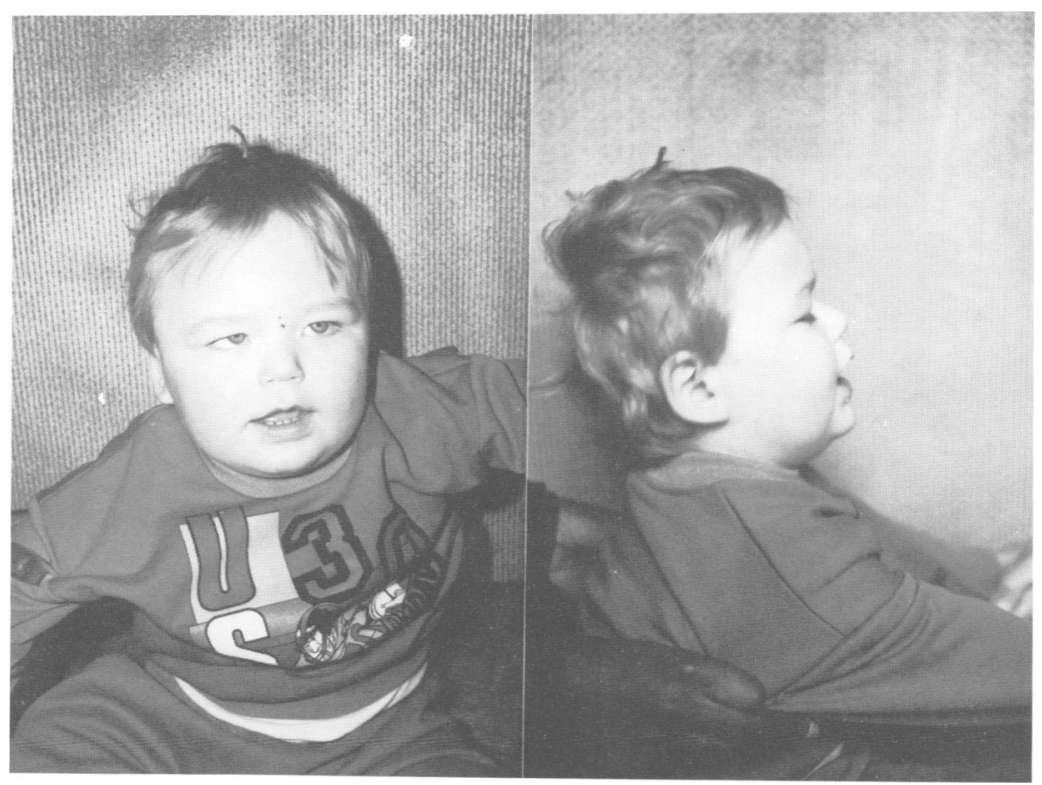

Figure 3 Case 2 aged 2 years. no evidence of the fragile site on the $\mathrm{X}$ chromosomes.

CASE 4

Case 4 (III. 5, fig 1) was born in 1969. Obstetric history and infancy were reportedly normal. She started mainstream school but was transferred to a school for children with special needs at the end of the first year. Like her sister (case 3 ) she is attractive and physically normal, with good social skills and presentation.

FAMILY HISTORY

There is no significant reported mental or physical illness in the family. The mother of the boys had a normal development and is mentally and physically normal, as is her mother. Karyotyping on several occasions showed a normal female 46,XX (700 BPHS).

\section{Discussion}

The two brothers with their craniofacial dysmorphism, mental retardation, and otherwise normal physical findings do not appear to fit into the more specific X linked mental retardation syndromes, such as the fragile $\mathrm{X}$ syndrome (Xq27 fragile site, macrogonadism, coarse features, bat ears, behavioural problems); Borjesson-Forssman-Lehman syndrome (mental retardation, extreme microcephaly, obesity, microgonadism, abnormal neurological status, characteristic amphora shaped facies, growth retardation); AllanHerndon syndrome (severe mental retardation, ataxia, athetosis, muscle hypoplasia, joint contractures, spastic paraplegia, elongated facies, and bitemporal narrowing with normal head circumference); Renpenning syndrome (mental retardation, short stature, microcephaly); Golabi-Rosen syndrome, etc. Congenital infections and metabolic causes were excluded in the older brother. $\alpha$ thalassaemia was excluded in the younger brother by the absence of $\mathrm{Hb} \mathrm{H}$ inclusions in red cells stained with cresyl blue. ${ }^{4}$

There are several possible explanations for the frequent occurrence of mental handicap in this family. The two boys could have an $\mathrm{X}$ linked syndrome and their two aunts a quite separate, possibly recessive, form of non-specific mental handicap. This seems inherently unlikely. Alternatively if the boys' mother carried a submicroscopic chromosome translocation in the balanced form, it would be possible for her sisters to have one unbalanced derivative of the translocation and her sons to have a different one. Despite repeated searches no such abnormality was found.

Finally this could be a new $\mathrm{X}$ linked dysmorphic mental handicap syndrome with only mild expression in the two aunts and no expression at all in the mother. We believe this to be the most likely mechanism.

We wish to thank the South East Thames Regional Cytogenetics Laboratory for their 
persistent karyotyping and Dr Ian Kenney for the skull $x$ ray of case 1 . 1 Bliumina MG. The frequency of X linked mental retard-
ation. Genetika 1989;25:1128-30.
2 Glass I. X linked mental retardation. $f$ Med Genet 1991;28:361-71.

3 Kerr B, Turner G, Mulley J, Gedeon A, Partington M. Nonspecified X linked mental retardation. F Med Genet

4 Editorial Alpha-thalassaemia/mental retardation. Lancet 1991;338: 1562-3. 